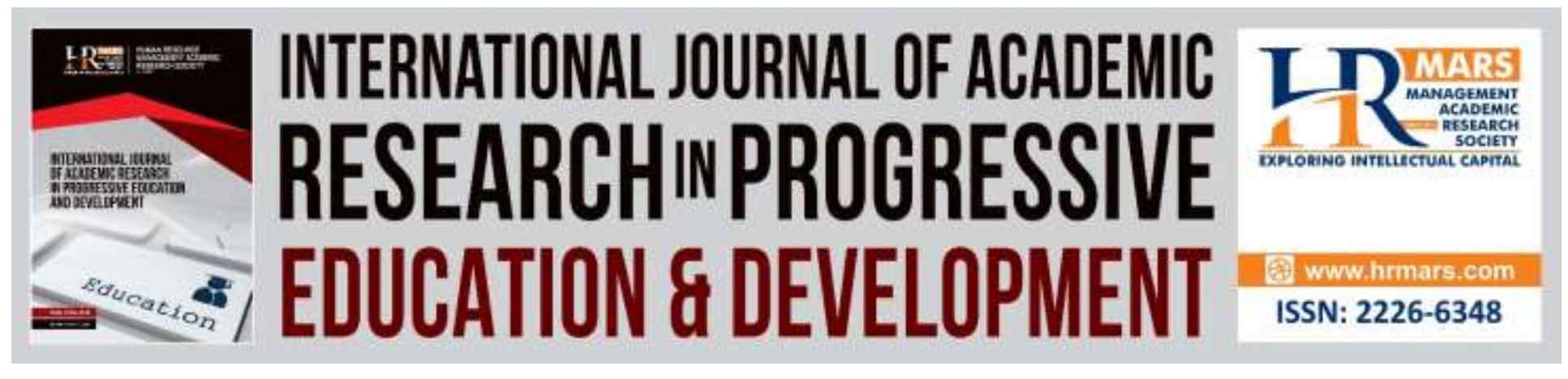

\title{
Research on Application of Computer Aided Translation to Translation Teaching
}

\author{
Lu Juan, Noraffandy Bin Yahaya
}

To Link this Article: http://dx.doi.org/10.6007/IJARPED/v8-i4/6722

DOI:10.6007/IJARPED/v8-i4/6722

Received: 10 November 2019, Revised: 29 November 2019, Accepted: 11 November 2019

Published Online: 31 December 2019

In-Text Citation: (Juan, \& Yahaya, 2019)

To Cite this Article: Juan, L., \& Yahaya, N. B. (2019). Research on Application of Computer Aided Translation to Translation Teaching. International Journal of Academic Research in Progressive Education and Development, 8(4), 795-804.

Copyright: (C) 2019 The Author(s)

Published by Human Resource Management Academic Research Society (www.hrmars.com)

This article is published under the Creative Commons Attribution (CC BY 4.0) license. Anyone may reproduce, distribute, translate and create derivative works of this article (for both commercial and non-commercial purposes), subject to full attribution to the original publication and authors. The full terms of this license may be seen at: http://creativecommons.org/licences/by/4.0/legalcode

Vol. 8(4) 2019, Pg. 795 - 804

http://hrmars.com/index.php/pages/detail/IJARPED JOURNAL HOMEPAGE

Full Terms \& Conditions of access and use can be found at http://hrmars.com/index.php/pages/detail/publication-ethics 


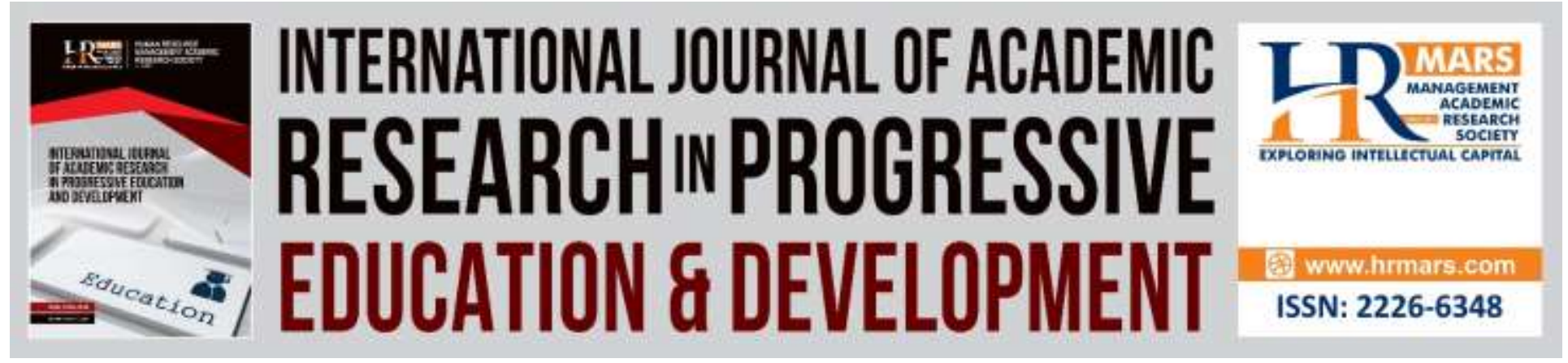

\title{
Research on Application of Computer Aided Translation to Translation Teaching
}

\author{
Lu Juan \\ School of Foreign Studies, Shaanxi University of Technology, China; School of Education, \\ Universiti Teknologi Malaysia, Malaysia \\ Email: Juanlu1981@graduate.utm.my
}

Noraffandy Bin Yahaya

(School of Education, Universiti Teknologi Malaysia, Malaysia)

Email: p-afandy@utm.my

\begin{abstract}
This research aims to do contribution for the application of computer-aided translation technology in the traditional translation teaching in universities. Compared with the arduous manual translation, computer-aided translation can increase translation efficiency. The application of computer-aided translation to translation teaching can improve the teaching quality and meet the massive demand of translation job market. Based on the development of CAT technology and its experiment in modern translation industry, the necessity of applying CAT technology in translation teaching is convincingly proven, which is followed by the elaboration on the design of CAT teaching modules and the construction of CAT teaching system in this research. This research investigated the application of CAT to translation teaching, including designing teaching mode, using software and hardware, managing teaching files, storing teaching resources, establishing the translation corpus and so on, which have great significances to translation teaching and translation practice. Finally, a conclusion is made that only when translation education combining with CAT Technology, can translation education meet the demand of increasing translation market, and only by applying CAT technology in translation teaching in universities, can the translation education catch up with the development of the translation industry in this information age.
\end{abstract}

Keywords: Computer-Aided Translation Technology, Translation Teaching, Machine-Readable Corpus

\section{The Status Quo of Cat Course Home and Abroad}

In China, there are only ten universities establishing CAT course: Peking University, Beijing International Studies University, Beijing University of Aeronautics \& Astronautics, Sun Yat-sen University, Beijing Foreign Studies University, Shandong Normal University, Hebei Normal 
University, Chinese University of Hong Kong, City University of Hong Kong and University of Macau. The purpose of CAT course in above-mentioned university is to help students learn about the principle and mechanism of machine translation and to be able to translate with at least one CAT tool. After learning this course, "students can be acquainted with the theory of terminology management and know how to create and use the terminology corpus as a translation tool. Generally speaking, the mode of the CAT course in these universities contains the following three essential parts.

1) The application of computational technology in the field of translation practice and theory, including the development of computational linguistics, natural language processing, English and Chinese word separation technology, as well as the practice and theory of corpus linguistics technology in the field of language and translation. In view of the fact that corpus linguistics is being paid more and more attention, corpus linguistics is the vital segment of this essential part, including its concept, necessity, history, characteristics, as well as text encoding and label, concordance program, introduction of important corpus, the application of corpus in language study and translation practice. The related softwares are Taiparse POS Tagger, Apple Pie Parser, Stantagger, Wordsmith Tools, Concapp and ParaConc.

2) Computer translation. It includes the system, the technology and the evaluation of machine translation and CAT tools, as well as the related software concerning CAT. The softwares are as follows: Systran, TransStar, Trados Work Bench, Yaxin CAT, and Wordfast \& Plustools.

3) Terminology management. This part includes what terminology and translation researchers should do in terminology management; how to build up bilingual or multilingual corpus; how to solve problems concerning translation using machine-readable corpus and digital reference. In this part, the related softwares are Babylon, Foreignword and Trandos Terminology.

In CAT course, the way of teaching is creative. In traditional translation teaching, it is teacheroriented, while the CAT course is student-oriented. The way that the teachers demonstrate while the students observe no longer exists in the course of Language and Translation Technology. Students do real-time practice under the teacher's instruction. When practicing, problems may be firstly encountered, and then reported; at last students got feedback from the teacher, and then problems are solved. It is best to arrange the teaching place of this course in the language lab equipped with students' terminal operation machines. If possible, students can take their own laptop so that teaching can happen in a common classroom. After-class homework and research project should be finished with the computer, personally owned or school owned, as the aiding tool.

\section{The Application of Computer-Aided Translation in Translation Teaching Theoretical Framework of the CAT Translation Teaching---Constructivism}

Language translation has often been described as one of the most impressive mental operations of the human mind in view of the complexity of grammatical structures, diction correlation, and multicultural transformation. As a result, various theories of translation teaching have influenced numerous approaches to translation learning. Widdowson pointed out, the effectiveness of translation teaching depends on proper theory as well as tactics of beneficial interaction in learning and teaching activities. For CAT translation teaching, the wide-accepted theory is constructivism. 


\section{Definition of Constructivism}

Fosnot (1989) gives the definition of constructivism according to the following four points: learning, in an important way, depends on what we already know; new ideas occur as we adapt and change our old ideas; learning involves inventing ideas rather than mechanically accumulating facts; meaningful learning occurs through rethinking old ideas and coming to a new conclusion about new ideas which conflict with our old ideas, so constructivism is a philosophy of learning founded on the premise that, by reflecting on our experiences, we construct our own understanding of the world we live in. Each of us generates our own rules and mental models, which we use to make sense of our experiences. Learning, therefore, is simply the process of adjusting our mental models to accommodate new experiences.

Constructivism promotes social and communicative skills by creating a classroom environment that emphasizes collaboration and exchange of ideas. Students must learn how to articulate their ideas clearly as well as to collaborate on tasks effectively by sharing in-group projects. Students must therefore exchange ideas and negotiate with others and then to evaluate their contributions in a socially acceptable manner. This is essential to success in the real world, since they will always be exposed to a variety of experiences in which they have to cooperate and navigate among the ideas of others.

\section{Contribution of Constructivism to the Research}

Firstly, Constructive theory advocates students-cantered learning and self-mental understanding, which promote this research to construct self-autonomous learning environment under the network background, which help students construct knowledge by themselves. Constructivists hold that knowledge can't be transmitted by teachers; instead it is actively constructed by learners in certain social and cultural context through interaction with other people including teachers and learning partners and by making use of necessary learning materials. Under the environment of network, students understand new knowledge by mentally correlating the unknown knowledge with the known knowledge (Rebeka, \& Majda, 2015). Learning new knowledge is based on the self-correlation process between the new knowledge and the old knowledge. During the mental self-correlation process, the new knowledge and the old knowledge interact with each other. Old knowledge and background information facilitate and promote students easily understand new knowledge while new knowledge improves and strengthens the better understanding of old knowledge, which is a kind of self-knowledge construction learning. Therefore, Constructivism enlightens the researcher to construct selfautonomous learning environment to propel students to digest knowledge by self-correlation and self-construction with the help of computer and network facility.

Secondly, constructive theory advocates task or case-based learning to actively solve problem instead of passively memorizing knowledge, and it stress on practice and practical competence rather than score in the exam, which propel this research to innovate the traditional knowledge transmission method by designing the Task-based and CAT-assisted translation teaching. In the old teaching mode, teacher is the dominant centre of the classroom, and teachers speak all the time while students just listen to teachers passively (Jianlin, 2017). However, in the new teaching model, students are impelled to construct knowledge themselves by assigning the task to them. When students make effort to finish their task, they learn the new knowledge with deep 
INTERNATIONAL JOURNAL OF ACADEMIC RESEARCH IN PROGRESSIVE EDUCATION AND DEVELOPMENT

Vol. 8, No. 4, 2019, E-ISSN: 2226-6348 @ 2019 HRMARS

understanding and improve their competence comprehensively during the self-construction process.

\section{CAT Teaching Aided by Computer Technology}

In traditional translation teaching class, the teacher is the host of the classroom and students just passively listen, but the invention of computer technology invert this class atmosphere to a new direction that students become the main body of the teaching, actively participate, practice, discuss and communicate with each other, which is helpful for improving translation teaching quality (Bowker, 2012).

In the designing of network courses website, a very popular tool is the Course Management System (CMS for short), Moodle, widely used in constructing network teaching environment. Moodle has abundant course management functions and provide effective management for network teaching in different ways, such as autonomic study, communication between learners, interaction between the teacher and students, homework management, test management and so on. Therefore, it plays a supportive role in network course teaching. As a mature platform that can be modified, Moodle offers a mature technology framework for information workstation, helping a great deal with the development of network translation teaching environment and improving the working efficiency.

\section{Interactive Full-View Network Teaching Mode}

College English Curriculum Requirements (For Trial Implementation) issued by General Office of Ministry of Education of the People's Republic of China in 2004 proposed that every higher education institution should make full use of multimedia and network technology, adopt new teaching mode to improve the former one which simply focuses on the teacher's teaching. The new teaching mode should be supported by modern information technology, especially network technology, exceeding the limitation of time and place to teach English and developing in a direction of guiding students to do personalized and individualized study. New teaching mode should also reflect the principle of English teaching, being practical, knowledge-oriented and interesting. It is best to arouse the enthusiasm of both the teacher and the students, especially in which the students' subject-position are stabilized. New teaching mode, technically speaking, is interactive, feasible and easy to operate.

In network teaching mode, the teacher may set some contexts and lead up the teaching content according to the teaching requirement as well as combining the visual sense with the auditory sense to enlighten students' ideas. The teacher and the students can communicate at any time by the point-to-point or point-to-area control command and operation, so as to talk individually or discuss in a group.

\section{Software and Hardware Environment}

The CAT teaching does not equal to the classrooms which are equipped with computer and internet. It needs professional software and hardware to process special translation task and corpus. The selection of software, hardware and translation corpus should be differentiated by 
students' major and linguistic level. To realize the interactive full-view network teaching environment, the relevant equipment of software and hardware should synchronously develop. Multimedia network needs a set of equipment with certain specifications which qualify the requirement of storing information resources, being able to establish teaching database with category. At the same time, students can at any time search for the resources offered by the teaching server and do translation drills with the translation software preinstalled in the equipment. While exercising, students may ask the teacher questions. After finishing the exercise, students submit online, and then the document will be automatically imported into the target database and the translated texts will be compared according to the similarity, which is listed in an order, such as the similarity (from highest similarity to the lowest of the texts) or the preinstalled key words (from highest repetitiveness to the lowest). This is helpful for teachers to compare and contrast the collected translated versions to show to students the different translated texts, some certain paragraphs or specific sentences. Different translated results are marked by different colours or fonts and the teacher set some key words or specific word order as the standard to visually and directly display the different versions. Students discuss in a group according to the planed or random arrangement (like rows and lines) by the teacher's operating the control panel. The students discuss by earphone and microphone with the teacher's commenting occasionally, realizing the communication between them all. The computer has access to the internet all the time for the teacher and students to check and seek for the background knowledge, character information or related events appearing in the translation materials, which raises the accuracy of the translation.

\section{After-class learning system}

In addition to the in class interactive full-view network teaching mode, after class, if having an account and a computer connecting the network, users can decide of their own time and place to learn courses. The teacher uploads the teaching video and courseware to the network centre and users are able to receive the notice of resource updating and watch them online. If users have any questions, they may leave messages for the teacher and communicate with him or her, so students' translation study and practice will break the bound of time, space and venue. Whenever it is and wherever the students are, they can study and practice translation through the after-class learning system. The change of the teaching mode is not merely the change of teaching activities or teaching methods. The most important reform is to change the conception of teaching, from teacher-oriented, the simple teaching mode in which the teacher teaches only linguistic knowledge and professional skills, to student-oriented, the mode aiming at training students' practical linguistic ability and autonomic learning ability, helping students to expand studying field and improving comprehensive competence. Interactive network teaching mode enriches the content of translation teaching, abundant in style, obvious in effect. Students trained by network teaching mode will have their ability improved, easier to adapt to the development and changes of society and are qualified for the various demand of the translation market. The after-class learning system will not only cultivate students' self-study ability, also develop their problem-solving ability, which contribute student's lifelong sustainable development in translation. 


\section{Developing CAT Software of Teaching Management and Translation Memory}

In CAT teaching mode, translation memory principles should be applied to realize the management of teaching files, and the teaching resources database should be established under the principle of translation memory system.

\section{Management of Teaching Files and Terminology}

Teaching files include students' academic file information, record of achievement, graduation thesis, items of approved materials, the teacher's teaching plan, activity summary, and the survey report, etc. The ways of managing teaching files adopted by the translation departments of higher education institutions in our country have to be further improved. With the enlargement of the university's enrolment in China, more members of staff who manage teaching files increased correspondingly, which requires managers to change the traditional way of writing or copying by hand to a new method of office automation with modern network technology.

Advanced technology and equipment are suggested to be gradually adopted in the work of teaching files management. Using unified software for documents and files management. With the help of the computer, the materials are automatically categorized, accomplishing the management of automatized statistics and searching, which will alleviate the workload of the managers, realizing the scientific management of teaching files and improving working efficiency (Chan, S.W., 2013). Meanwhile, with the development of the network, the information of teaching files can be transmitted. The department of files management should also build teaching files database for better searching, classifying and managing these teaching files. The terminology management is another important factor in CAT teaching mode. The CAT software users have to set up one or more standard terminology lists (including the source language and the target language) for translators to take reference, and then CAT software can automatically recognize the new terminology and compare it with the existing one, offering translators a referable terminology translation. The terminology-management system compares the individual terms contained in each source text segment with the terms contained in the term base. If a term is recognized as being in the term base, the translator's focus will turn to the fact that this term has an entry, and the term record will be checked and inserted directly into the target text. This process means that when the translator cannot find the exact or fuzzy matches for source-text segments, some translation equivalents may at least appear for individual choice in the terminology-management system's term base.

\section{Translation Memory and Teaching Resources}

Similar to the management of teaching files, teaching resources database should be established under the principle of translation memory system. Translation memory technology is based on the notion of reusing previous translated segment. Translation memory system can establish database to store proper nouns, set phrases and sentences that appear with highly frequency. When students do translation, the database automatically shows the stored information to CAT users for reference. So, the students can share the resource and seek help from the translation memory database. For example, the translated texts of different versions, large quantities of exercises, great amount of courseware, drills, audio and video resources, all 
materials the teacher used in translation teaching class can be stored into the teaching resources database, ready for sharing.

Students can translate their assignment by themselves at the beginning, if they encounter any difficulties, they can refer to translation corpus to find answers. If any language point or knowledge information is needed, the database will automatically offer the teacher and students relevant materials. After finishing their assignment, students can compare their work with the different translation version which are stored in the corpus in advance. While comparing different translation version of the same translation task, students can contrast the advantages and disadvantages of their work with others, which facilitate them to appreciate translation from different perspective with different theoretical framework. Furthermore, other related resources also help students broaden their view and enlarge their studying field. Besides sharing the teaching resources, the teacher can constantly supplement and update the resource database, upload the individually prepared and concluded teaching materials as well as the excellent courses of state-level, province-level and university-level to the database. Network classroom and open courses should be established for the convenience of the students who can directly watch or download video resources from teaching database. They can listen to the teacher to learn knowledge at any time and at any place.

\section{Project-oriented Overall Teaching}

Project-oriented overall teaching refers to the teaching activity realized by working with a whole project in the form of group discussion or collaborative learning, during which the process of students' learning is the process of exploring. This kind of teaching method is especially suitable for the teaching under the computer network environment (Kelle, 2015).

Before the formal beginning of translation work, it is necessary to set up, analyse and premanipulate the translation project. Under the network environment, translation cooperation, through aiding tools and the network, is supposed to be collaboratively finished by all group members, and then the person in charge of gathering and managing the results of all groups should complete the whole project. The establishment, management of the project and the innovation of the database should be the responsibility of the project coordinator. Translation memory database and terminology database are the essential components of translation memory, which store all kinds of translation materials collected by the translators. During the whole process of translation, the existed database can be linked, and the new database can be created whenever needed. The project management system of the software may track the proceeding of the task and manage all the figures to coordinate the invocation, innovation and storage of the data. In the process of collaboration translation project, each member of the group exchanges the translation memory database and terminology database with each other, regularly updating personal database, which ensures the consistency of the terminology. Thus, translation quality is guaranteed. In conclusion, the process of CAT teaching project can be divided into three stages: preparation stage, translation stage and quality control stage. Most of the CAT software has quality inspection function that guarantees translation quality. For instance, the software Déjà Vu provides several layers of terminology consistency checking, including the consistency of terminology, figures, control codes and the whole sentence between 
the source language and the target language. The system can also check the translation version of terminology and sentences during translation process. If the existed one is inconsistent with the translated one, the system will mark it to remind the translator. The software itself cannot understand what the language means, the way it points out the translation difference is mechanic, but it really saves the translator's time and guarantees the translation quality.

\section{Conclusion}

The working principle of CAT technology and its practical technique operation have an enormous potential in development. Almost all the CAT programs mentioned in this paper keep upgrading and updating over the years and new technologies and new applications keep emerging, gaining more and more users. The talent demand from translation market is increasing, and the standard for new technology applying to translation field is becoming higher and higher. So, the computer hardware and software (mainly the operating system and the CAT tools) have to be improved urgently; at the same time, enhancing user's understanding of this technology has become the motivation of developing more efficient CAT systems. Besides, institutions of higher education need to renovate their traditional ways of teaching, and should adapt new educational philosophy, teaching approaches, and set new goals in translation education; they should also reform scheme of the courses, re-design the teaching process and pay more attention to the development of the CAT technology.

Although there are some problems in the course design and the study scheme in the CAT teaching program, revolution and progress are being made step by step; Although the CAT technology is not so perfect for teachers and students, it is improved and matured day by day; Although the CAT teaching in China is not so popular in translation education field, with a better understanding of the benefits and contribution of information technology, CAT translation teaching in China will be widespread popularized in the future. Anyway, with the increasing translation demand in China's translation market and the rapid development in scientific technology, it's the irresistible trend that translation expertise must be realized by combing language foundation, translation theory and information technology. In the CAT teaching program, we must note that The CAT technology is the prerequisite, the reform of teaching mode is the foundation and the change of study method is the core (Sager, 2012).

\section{References}

Bowker, L. (2012). Computer-aided translation technology: a practical introduction. University of Ottawa Press.

Chan, S. W. (2013). A Topical Bibliography of Computer aided Translation. The Chinese University Press.

Jianlin, C. (2017). Integration of computer network and foreign language curriculum: a study based on college English teaching reform. Shanghai: Shanghai foreign language education press.

Kelle, U. (2015). Computer-aided Qualitative Data Analysis: Theory, Methods and Practice. Sage Publications Limited. 


\section{INTERNATIONAL JOURNAL OF ACADEMIC RESEARCH IN PROGRESSIVE EDUCATION AND}

DEVELOPMENT

Vol. 8, No. 4, 2019, E-ISSN: 2226-6348 @ 2019 HRMARS

Rebeka, L., \& Majda, K. (2015). Exploring Non-traditional Learning Methods in Virtual and Realworld Environments. Educational Technology \& Society, 46(1), 237-247.

Sager, J. C. (2012). Language engineering and translation: Consequences of automation. John Benjamin.

Twomey, C. (1989). Enquiring Teachers, Enquiring Learners: A constructivist Approach for Teaching. New York: Teachers College Press.

Widdowson, H. G. (1995). Teaching Language as Communication. Oxford: Oxford University Press. 